\title{
HYDROGEN CHARGING OF FUEL CLADDING METHODOLOGY
}

\author{
Jakub KrejČÍ ${ }^{a, *}$, Jitka KabÁtová ${ }^{b}$, Jan KoČí $^{b}$, ZuZana Weishauptovác ${ }^{c}$, \\ VĚra VRTÍLKOVÁ ${ }^{b}$ \\ ${ }^{a}$ Department of Nuclear Reactors, Faculty of Nuclear Sciences and Physical Engineering, Czech Technical \\ University in Prague, Czech Republic \\ ${ }^{b}$ UJP Praha, a.s., Prague, Czech Republic \\ ${ }^{c}$ Department of Geochemistry, Institute of Rock Structure and Mechanics, Czech Academy of Sciences, v.v.i., \\ Prague, Czech Republic \\ * corresponding author: krejci.jakub@seznam.cz
}

\begin{abstract}
Hydrogen content is a very important parameter for mechanical properties of fuel cladding, especially after LOCA transients. Therefore, it is necessary to take into account the amount of hydrogen absorbed in the fuel cladding during normal operation (before a hypothetical LOCA). The required value of hydrogen content is possible to reach by a long-term pre-oxidation test or a much shorter hydrogen charging experiment. The methodology of hydrogen charging developed in UJP is described in this contribution. Results of experiments aiming to prepare samples with uniform hydrides and samples with a rim-layer and other hydrides are shown.
\end{abstract}

KEYwORDS: fuel cladding, hydridation.

\section{INTRODUCTION}

Thanks to a low absorption of neutrons and corrosion resistance zirconium alloys are an indispensable material for nuclear fuel cladding tubes. However, their mechanical properties deteriorate during operation in the reactor conditions, where corrosion reactions take place leading to the formation of oxide layers and also to dissolution and precipitation of hydrogen, and the formation of hydrides [1]. Zirconium hydrides are brittle, and can initiate crack and fissure formation in the alloy. Hydrogen also has a considerable effect on the ductility of the cladding, after a hypothetical LOCA (Loss of Coolant Accident). Much attention has been focused on this topic worldwide [2, 3].

The requirement of sufficient fuel rod strength upon quench taking into account an additional mechanical load is used regarding to the brittle mode, which is associated with cladding oxidation in the presence of steam at high temperature. This requirement led to a new equivalent cladding reacted (ECR) design limit based on LOCA semi-integral tests developed by JAEA (Japan Atomic Energy Agency). This criterion is expressed as a function of in-reactor hydrogen pickup [3, 4]. Alternative K-criterion and O-beta criterion for E110 alloys were developed in UJP [5, 6] also. Both are applicable for specimens with hydrogen content.

The presented study shows the methodology of hydrogen charging developed in UJP. Samples with uniform hydrides and specimens with rim-layer and other hydrides are shown. Double-sided and singlesided hydrogen charging is presented.

\section{EXPERIMENTAL AND METHODOLOGY}

\subsection{SPECIMENT PREPARATION}

All samples examined in this study were fabricated of the E110 alloy. The chemical composition is presented in Table 1

\begin{tabular}{cccccc}
\hline $\begin{array}{c}\text { wt. } \\
{[\% / \mathrm{ppm}]}\end{array}$ & $\begin{array}{c}\mathrm{Nb} \\
{[\%]}\end{array}$ & $\begin{array}{c}\mathrm{H} \\
{[\mathrm{ppm}]}\end{array}$ & $\begin{array}{c}\mathrm{O} \\
{[\mathrm{ppm}]}\end{array}$ & $\begin{array}{c}\mathrm{Hf} \\
{[\mathrm{ppm}]}\end{array}$ & $\mathrm{Zr}$ \\
\hline $\mathrm{Zr} 1 \mathrm{Nb}$ & 1.0 & 3 & $<400$ & 400 & balanced \\
\hline
\end{tabular}

TABLE 1. The chemical composition of studied alloy.

The tested tubular specimens had the following dimensions: outside diameter $\sim 9.1 \mathrm{~mm}$ and wall thickness $\sim 686 \mu \mathrm{m}$. For double-sided hydrogen charging $30 \mathrm{~mm}$ or $90 \mathrm{~mm}$ long non-irradiated segments were used, which were cleaned, degreased, and then weighted, and measured (length, diameter).

For single-sided hydrogen charging $90 \mathrm{~mm}$ long nonirradiated segments and end-plugs made of a rod from the same material were used. The tube-part and endplugs were welded together using the electron beam welding method. These specimens were cleaned, degreased, and then weighted and measured (length, diameter). After that, the samples were filled with inert gas (argon) at required inner pressure (0-12.5 MPa), and welded in a pressure chamber. The procedure of welding was developed in UJP, and the device can be seen in Fig. 1

The samples were weighted after welding, and based on the mass gain of inner gas the inner pressure was recalculated. 


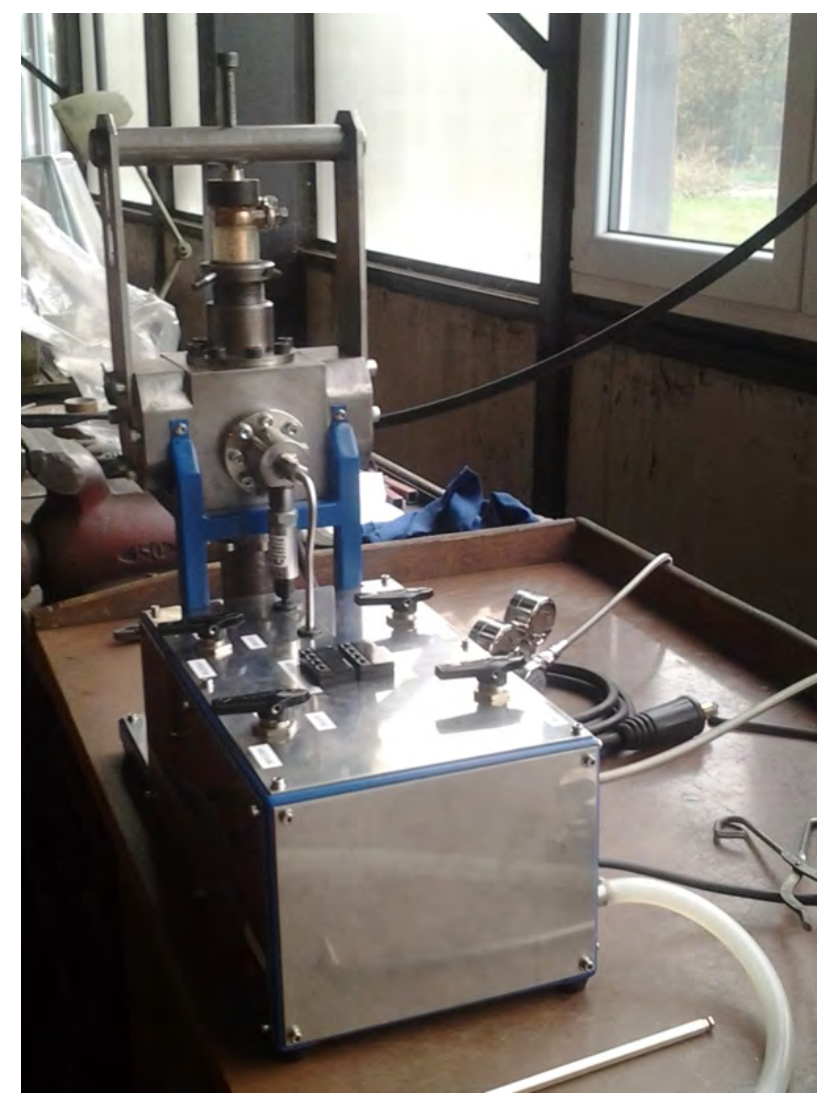

Figure 1. Device used for-welding samples.

\subsection{HydRogen CHARGING USING GRAVIMETRIC SORPTION ANALYZER}

Double-sided hydrogen charging was performed in cooperation with The Institute of Rock Structure and Mechanics of the Czech Academy of Sciences, and it was published in 2015 [2]. The hydrogen charging was carried out using a microscale of an IGA 002 gravimetric sorption analyzer (Hiden).

A sample was placed into the reactor chamber of the instrument by hanging it vertically on the microscale beam, and the entire system was evacuated at a temperature of $200^{\circ} \mathrm{C}$. Hydrogen charging was carried out by hydrogen of 99.9999 vol. \% purity at a temperature of $405^{\circ} \mathrm{C}$ and pressure of $0.1 \mathrm{MPa}$. The mass changes of the sample and the thermodynamic conditions of the process were observed during hydrogen charging. An example of the course of the hydrogen charging process is presented in Fig. 2 After the required mass gain was reached, a hydride layer was observed on the surface of the samples with the higher hydride concentration.

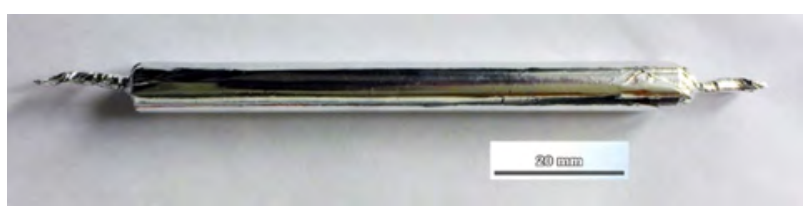

Figure 2. Sample packed in aluminum foil.

\subsection{Autoclave Charging}

An alternative method for hydrogen charging was developed in UJP. The autoclave method provides the possibility to charging bigger amount of samples together. Target amount of hydrogen content is up to $600 \mathrm{ppm}$ for PWR conditions (ZIRLO $70 \mathrm{GWd} / \mathrm{t}[3]$ ), and up to $120 \mathrm{ppm}$ for E110 in VVER environment ( $\sim 5$ years in reactor conditions).

Specimens were packed in an aluminum foil, which was used as a protection against oxidation, see in Fig. 2

The prepared samples were placed in the autoclave with an inner volume of about $4.5 \mathrm{dm}^{3}$. The hydrogen charging was carried out by hydrogen of 99.9999 vol. $\%$ purity at a temperature of $350{ }^{\circ} \mathrm{C}$, and pressure of about $0.1 \mathrm{MPa}$. The temperature and the pressure in the autoclave during the hydrogen charging process are shown in Fig. 3 .

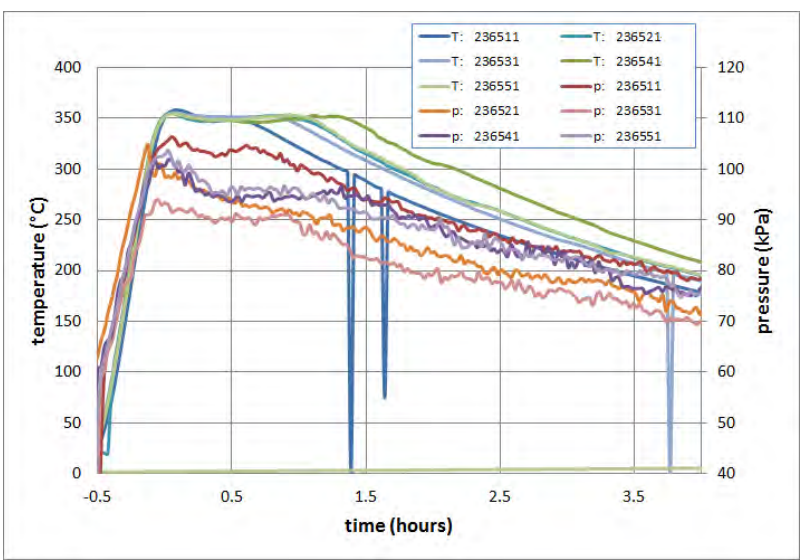

FiguRE 3. Temperature and pressure during hydridation process.

After the hydrogen charging process as the aluminum foil was removed, a hydride layer and oxide layer was observed on the surface of the samples, see in Fig. 4 .

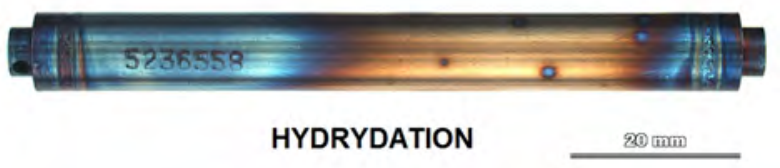

FiguRE 4. The typical outlook of specimen after hydrogen charging process.

Samples were weighted after, and based on the mass gain the hydrogen pick-up was calculated. The following form is used for calculation. It presumes, that the whole mass gain corresponds to hydrogen pick-up

$$
H=\frac{\frac{\Delta m}{V_{0}}}{\frac{\Delta m}{V_{0}}+\frac{m_{0}}{V_{0}}} \times 10^{6}=\frac{1}{1+\frac{m_{0}}{\Delta m}} \times 10^{6},
$$

where $H$ is hydrogen content in ppm, $\Delta m$ is mass gain during hydridation, $m_{0}$ is initial weight and $V_{0}$ is sample volume. 


\subsection{VACUUM ANNEALING}

The dissolving of hydride-layer was processed in a vacuum furnace (CLASIC). At a pressure about $10^{-6} \mathrm{bar}$, and temperatures of about $575{ }^{\circ} \mathrm{C}$ were used for annealing. The length of the exposure time was chosen up to 6 hours of duration.

An influence of the temperature and the exposure time on the hydride-layer dissolution was observed. The surface of the samples after annealing was the same as before the charging process, as can be seen in Fig. 5 .

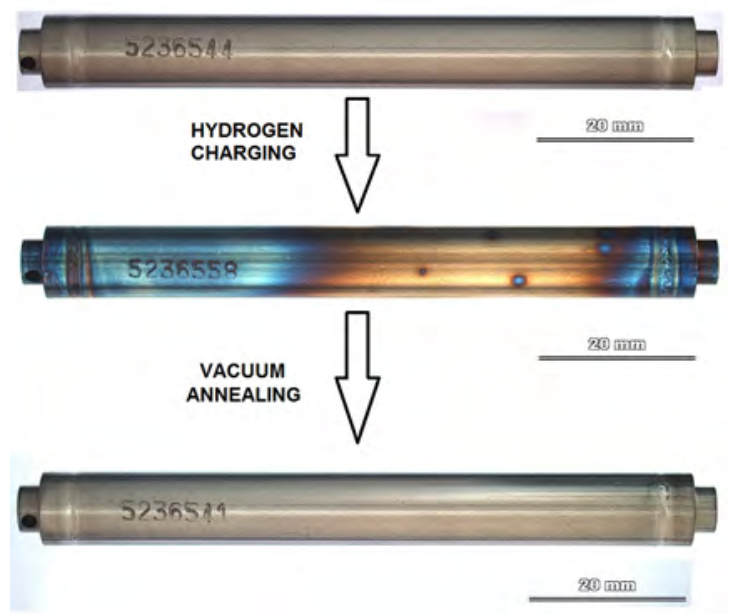

FiguRE 5. The typical outlook of specimen before and after vacuum annealing process.

The samples were weighted after the vacuum annealing, and based on the mass loss the hydrogen pick-up was recalculated. For calculation of hydrogen content is used the equation (1), where $\Delta m$ is mass gain after annealing.

\subsection{Metallographic observations}

Parts of the samples intended for a metallographic evaluation of the hydrides were fixed in epoxy resin, were prepared using a standard polishing procedure, and were etched after. On the prepared metallographic sections, the hydrides were observed and evaluated using a NIKON EPHIPHOT 300 light microscope and a LUCIE image analyzer.

\subsection{Hydrogen CONTENT MEASUREMENTS}

Parts of the samples intended for hydrogen content measurements were analyzed using the Analyzer G8 GALILEO (Bruker), which works on the inert gas fusion (IGF) principle.

\section{Results}

\subsection{UNIFORM DISTRIBUTION OF HYDRIDES}

Preparation of specimens with uniform distribution of hydrides was one of the objectives of the presented work. The methodology consisting of autoclave charging and vacuum annealing was applied on the sample CH21. A predicted hydrogen content value - based on weight gain and calculation - was evaluated at 123 wppm. It was in a good agreement with the experimental value gained using the G8 GALILEO, which was 135 wppm. A satisfactory dissolution of the hydride-layer was observed after 90 minutes of annealing in the vacuum furnace at a temperature of $575^{\circ} \mathrm{C}$.

\section{CH21.2 EPI 10} $100 \mu \mathrm{m}$

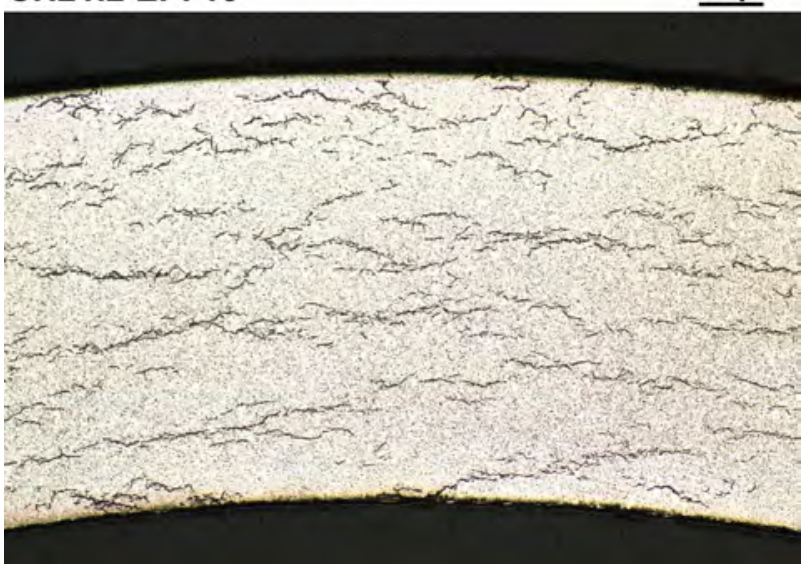

Figure 6. Sample CH21 was prepared using methodology for uniform distribution of hydrides.

\subsection{InFLUENCE OF VACUUM ANNEALING}

The gravimetric sorption method was used for doublesided hydrogen of the sample 1H001. This sample was cut into 7 segments which were used for hydrogen content measurements and for experiments focused on the influence of the annealing parameters. The predicted hydrogen content value - based on the weight gain during the hydrogen charging - was evaluated at 540 wppm. It was in a very good agreement with the experimental value gained using the G8 GALILEO, which was $544 \mathrm{wppm}$. Vacuum annealing conditions for several segments of the sample were described in Table 2 .

\begin{tabular}{|c|c|c|c|}
\hline Segment & $\begin{array}{c}\text { Temperature } \\
{\left[{ }^{\circ} \mathrm{C}\right]}\end{array}$ & $\begin{array}{c}\text { Exposure time } \\
\text { [min] }\end{array}$ & Figure \\
\hline $1 \mathrm{H} 001-6$ & No annealing & No annealing & 7 \\
\hline $1 \mathrm{H} 001-4$ & 350 & 20 & 8 \\
\hline 1H001-3 & 575 & 20 & $\overline{9}$ \\
\hline 1H001-1 & 575 & 60 & 10 and 11 \\
\hline
\end{tabular}

TABLE 2. The sample 1H001, annealing conditions.

The sample 1H001-6 was processed for hydrides evaluation after the hydrogen charging process. Hydride layers and a uniform distribution of hydrides in the sample were found (Fig. 7). The detail of sample numbered 1H001-4 did not show any observable hydridelayer dissolution (Fig. 8). An observable beginning of the hydride-layer dissolution was seen for detail the sample numbered 1H001-3 (Fig. 9). The metallographic evaluation of sample numbered 1H001-1 
showed the hydride-layer in an advanced state of dissolution (Fig. 10), or the whole hydride-layer dissolved (Fig. 11).

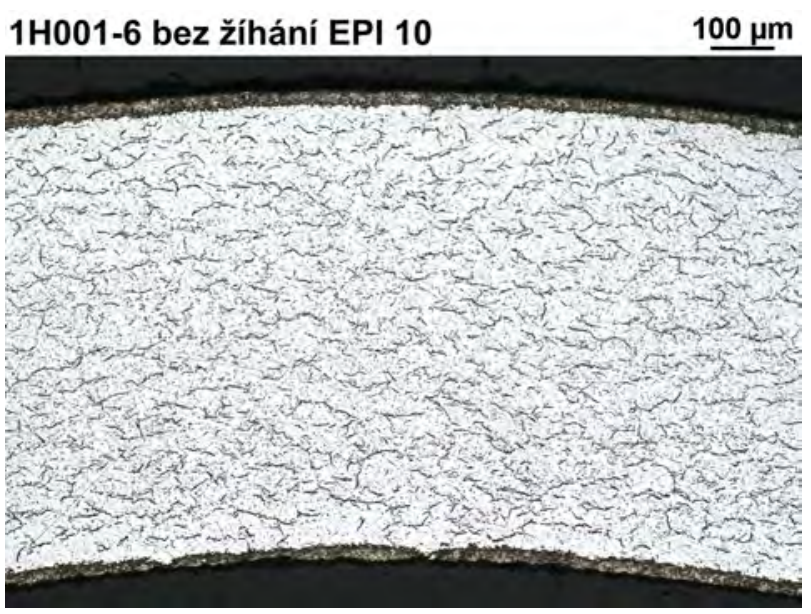

Figure 7. Sample 1H001, section 6. Prepared after hydrogen charging (without annealing).

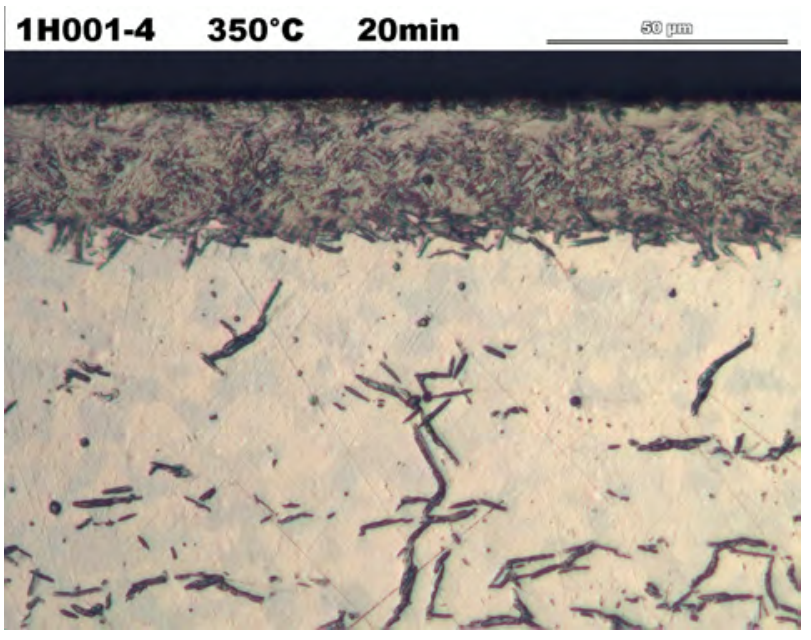

FiguRE 8. Sample 1H001, section 4. After hydrogen charging was used annealing at temperature $350{ }^{\circ} \mathrm{C}$ and 20 minutes of time duration.

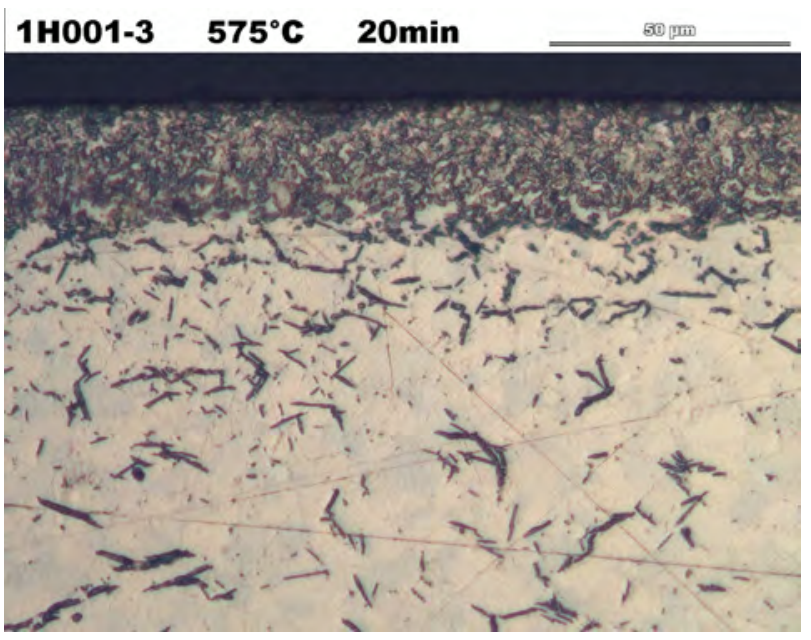

Figure 9. Sample 1H001, section 3. After hydrogen charging was used annealing at temperature $575^{\circ} \mathrm{C}$ and 20 minutes of time duration.

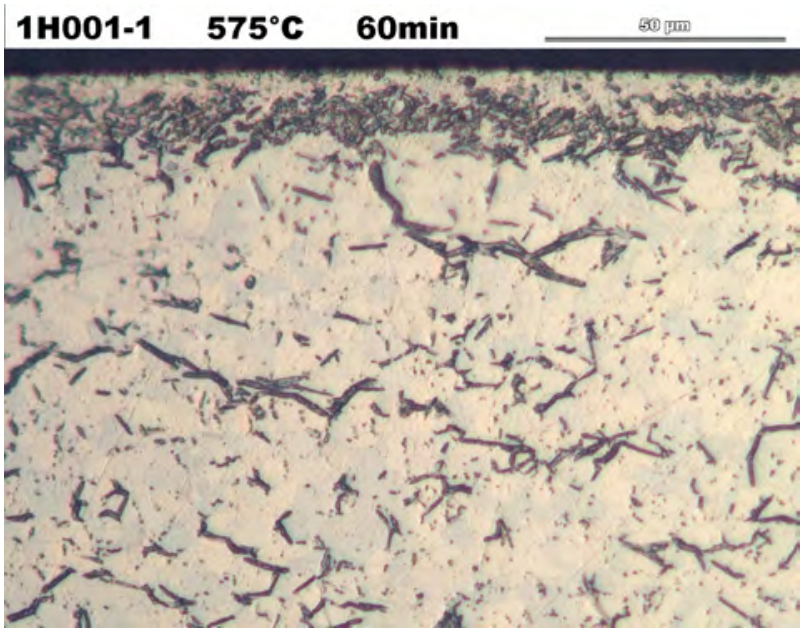

Figure 10. Sample 1H001, section 1, detail B. After hydrogen charging was used annealing at temperature $575^{\circ} \mathrm{C}$ and 60 minutes of time duration.

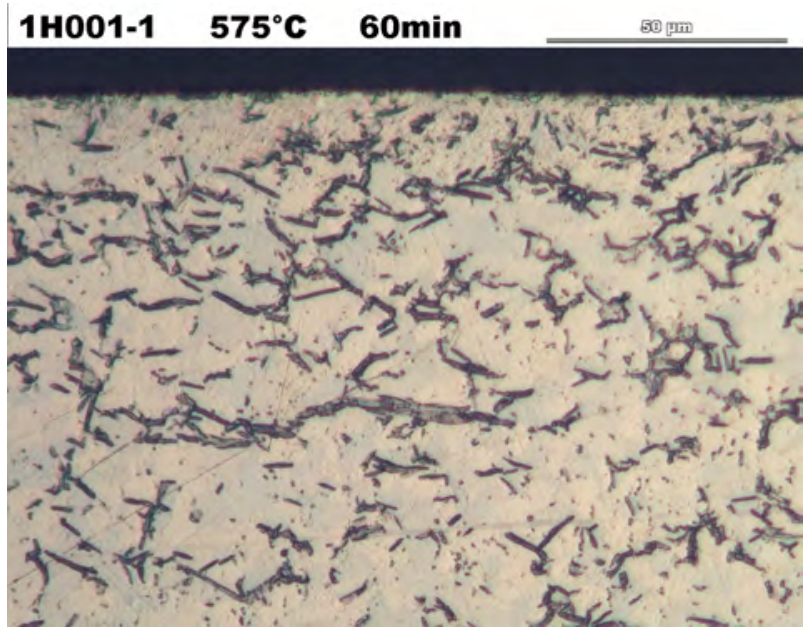

Figure 11. Sample 1H001, section 1, detail A. After hydrogen charging was used annealing at temperature $575^{\circ} \mathrm{C}$ and 60 minutes of time duration.

\subsection{INFLUENCE OF INNER PRESSURE}

The mechanical properties of the fuel cladding depend not only on the hydrogen content, but as well on the orientation of the hydrides. Radial hydrides can appear in some specific cases of operation, which can initiate a crack and failure of the fuel cladding. Precipitation of radial hydrides was observed during slow cooling of heated samples with inner gas pressure under the temperature of hydrogen dissolution.

After hydrogen charging were samples cut into segments. Two were used for hydrogen content evaluation and one for metallography. The experimental values of hydrogen content gained using G8 GALILEO, were 328 wppm (829 447), and $393 \mathrm{wppm}$ (829 463).

The number of radial hydrides is directly connected with the value of applied stress, which is caused by the inner gas pressure. Figures 12 and 13 show hydrides distributions for several values of inner pressure. An outer hydride-layer was observed in all cases and 
for samples with inner pressure, especially sample numbered 829463 , radial hydrides were observed. Radial hydrides for inner pressure of $0.05 \mathrm{MPa}$ were not observed. The number of radial hydrides was evaluated as $34 \%$ for 829447 (inner pressure at $20^{\circ} \mathrm{C}-$ $3 \mathrm{MPa}$ ), and $70 \%$ for 829463 (inner pressure at $20^{\circ} \mathrm{C}$ $-9 \mathrm{MPa})$.

\section{EPI 10}

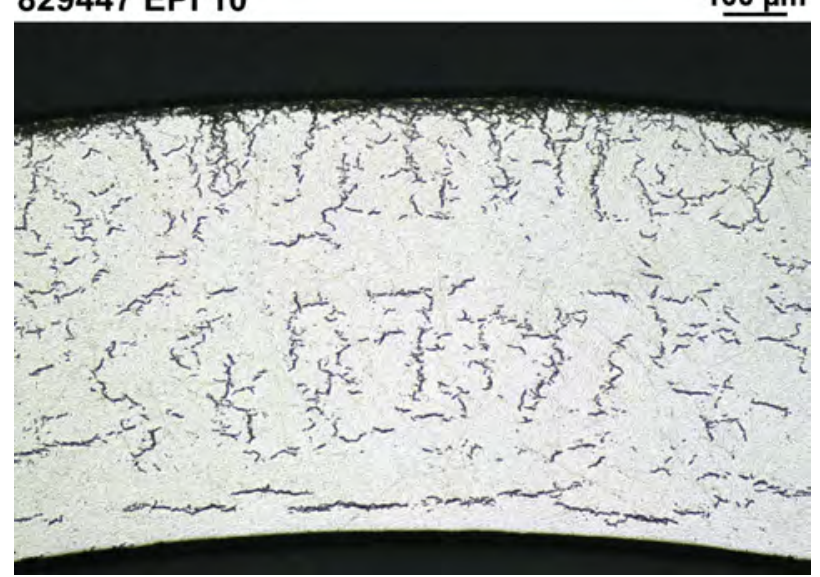

Figure 12. Sample 829447 . After hydrogen charging with inner pressure $3 \mathrm{MPa}$.

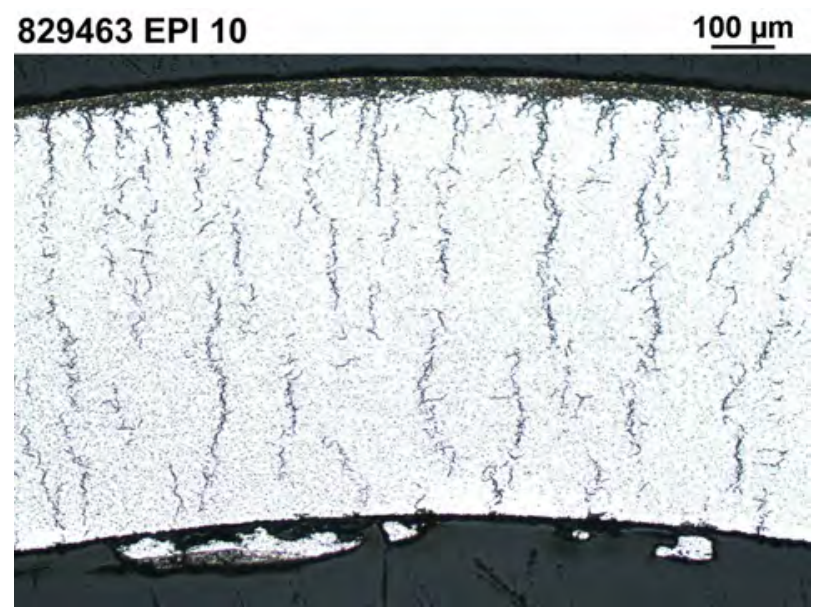

Figure 13. Sample 829463 . After hydrogen charging with inner pressure $9 \mathrm{MPa}$.

\section{Conclusions}

The experiments have shown that a requested hydrogen content and a uniform distribution of hydrides can be reached using hydrogen charging, and a further vacuum annealing procedure.

Influence of temperature and time exposure of vacuum annealing was observed. The experiments have shown the level of hydride-layer dissolution under several conditions.
Radial hydrides were observed during experiments with inner pressure. A large amount of radial hydrides, about $70 \%$, were observed for an inner pressure value which can be possibly reached in reactor conditions also.

This contribution presented the methodology used for hydrogen charging in UJP. Prepared samples is possible to use for LOCA experiments focused on testing material deteriorated during operation in the reactor conditions.

Future works will be focused on a more detailed elaboration of several topics. A quantitative evaluation of hydride-layer dissolution and radial hydrides precipitation will be provided.

\section{ACKNOWLEDGEMENTS}

The authors would like to thank to J. Šustr, J. Sýkora, V. Rozkošný, F. Manoch, and M. Štukbauer for the samples, and metallographic sections preparation, and for the hydrogen content evaluation. Financial support for this research through grants No. CZ.2.16/3.1.00/21563 and "TA02011025, program ALFA - TAČR" is gratefully acknowledged.

\section{REFERENCES}

[1] H.-H. Hsu. An evaluation of hydrided Zircaloy-4 cladding fracture behavior by X-specimen test. Journal of Alloys and Compounds 426(1-2):256-262, 2006. DOI:10.1016/j.jallcom.2005.12.113.

[2] Z. Weishauptová, J. Navrátilová, V. Vrtílková. The influence of hydrogen on high temperature oxidation of Zr1Nb cladding tubes. In Conference TopFuel 2015, Proceedings - Poster, pp. 319-326. 2015. https://www . euronuclear.org/events/topfuel/ topfuel2015/transactions/ topfuel2015-transactions-poster.pdf

[3] Y. Yan, T. Burtseva, M. Billone. Recent results at argonne on post-quench ductility of high-burnup cladding. In Fuel Safety Research Meeting. Japan Atomic Energy Agency, 2009.

[4] S. Boutin, S. Graff. A new LOCA safety demonstration in France. In Conference TopFuel 2015, Proceedings Part II, pp. 440-449. 2015. https://www .euronuclear. org/events/topfuel/topfuel2015/transactions/ topfuel2015-transactions-oral-2.pdf.

[5] V. Vrtílková, L. Novotný, R. Doucha, J. Veselý. An approach to the alternative LOCA embrittlement criterion. In Proceedings of SEGFSM Topical Meeting on LOCA Fuel Issues. 2004. https://www. oecd-nea. org/nsd/docs/2004/csni-r2004-19.pdf

[6] M. Négyesi, V. Klouček, J. Lorinčík, et al. Proposal of new $\mathrm{o}_{\beta}$ oxidation criterion for new types of the $\mathrm{Zr} 1 \mathrm{Nb}$ alloy of fuel claddings. Nuclear Engineering and Design 261:260-268, 2013.

DOI:10.1016/j.nucengdes.2012.09.033 